NBER WORKING PAPER SERIES

\title{
DO HOSPITAL-OWNED SKILLED NURSING FACILITIES PROVIDE BETTER POST-ACUTE CARE QUALITY?
}

Momotazur Rahman

Edward C. Norton

David C. Grabowski

Working Paper 22515

http://www.nber.org/papers/w22515

\author{
NATIONAL BUREAU OF ECONOMIC RESEARCH \\ 1050 Massachusetts Avenue \\ Cambridge, MA 02138
}

August 2016

We would like to thank Christian Brostrup-Jensen and other members of CGHCR for helping us with data retrieval. We are grateful for comments by Guy David and to seminar participants at the London School of Economics, ASHEcon, CIRANO (Montreal), Tulane University and Texas A\&M University. The views expressed herein are those of the authors and do not necessarily reflect the views of the National Bureau of Economic Research.

NBER working papers are circulated for discussion and comment purposes. They have not been peer-reviewed or been subject to the review by the NBER Board of Directors that accompanies official NBER publications.

(C) 2016 by Momotazur Rahman, Edward C. Norton, and David C. Grabowski. All rights reserved. Short sections of text, not to exceed two paragraphs, may be quoted without explicit permission provided that full credit, including ()$^{\text {notice, }}$ is given to the source. 
Do Hospital-Owned Skilled Nursing Facilities Provide Better Post-Acute Care Quality?

Momotazur Rahman, Edward C. Norton, and David C. Grabowski

NBER Working Paper No. 22515

August 2016

JEL No. I11,I18

\begin{abstract}
As hospitals are increasingly held accountable for patients' post-discharge outcomes under new payment models, hospitals may choose to acquire skilled nursing facilities (SNFs) to better manage these outcomes. This raises the question of whether patients discharged to hospital-based SNFs have better outcomes. In unadjusted comparisons, hospital-based SNF patients have much lower Medicare utilization in the 180 days following discharge relative to freestanding SNF patients. We solved the problem of differential selection into hospital-based and freestanding SNFs by using differential distance from home to the nearest hospital with a SNF relative to the distance from home to the nearest hospital without a SNF as an instrument. We found that hospital-based SNF patients spent roughly 5 more days in the community and 6 fewer days in the SNF in the 180 days following their original hospital discharge with no significant effect on mortality or hospital readmission.

Momotazur Rahman

Center for Gerontology and Health Care Research

121 South Main Street, S-6

Providence, RI-02912

momotazur_rahman@brown.edu

Edward C. Norton

Department of Health Management and Policy

Department of Economics

University of Michigan

School of Public Health

1415 Washington Heights, M3108 SPHII

Ann Arbor, MI 48109-2029

and NBER

ecnorton@umich.edu

David C. Grabowski

Harvard University

Department of Health Care Policy

Harvard Medical School

180 Longwood Avenue

Boston, MA 02115

grabowski@med.harvard.edu
\end{abstract}




\section{Introduction}

Medicare skilling nursing facility (SNF) care has been a major focus of recent policy discussions because, although they provide valuable care for many, they also serve as a substitute for both more expensive and less expensive types of care (Newhouse 2013). In the context of poor outcomes such as long SNF stays and high rates of hospital readmissions, some have questioned the underlying value of these services given their high cost to the Medicare program (Ackerly and Grabowski 2014). One factor that has potentially contributed to poor outcomes is the fragmentation in delivery between hospitals and SNFs. One recent study suggested that stronger hospital-SNF linkages, independent of common ownership, were found to reduce rehospitalization rates (Rahman et al. 2013a). As hospitals are increasingly held accountable for patients' post-discharge outcomes under new payment models, hospitals may choose to acquire SNFs to better manage these outcomes. An open research question is whether patients who go to hospital-based SNFs have better outcomes at lower episode costs than patients who go to nonhospital-based SNFs.

The number of hospital-based SNFs has ebbed and flowed over the decades in response to policy changes. As way of background, Medicare covers medical care for older adults including hospital and post-acute care services, while Medicaid is a means-tested programs that covers chronic nursing home care. As a bit of history, hospital-based ${ }^{1}$ SNFs were largely an afterthought in the 1970s and early 1980s when Medicare reimbursed inpatient hospital care on a cost-based basis. However, when Medicare shifted to the inpatient prospective payment system (PPS) in 1982, hospitals were paid a fixed amount per discharge and they were no longer

\footnotetext{
${ }^{1}$ The colloquial term in the literature for hospital-owned skilled nursing facilities (SNFs) are "hospital-based" SNFs. We acknowledge that some hospital-owned SNFs are not technically based in the hospital, but given the widespread use of this term, we employ the term hospital-based in this study to encompass all SNFs owned by a hospital even if they are located outside of the hospital campus.
} 
incentivized to provide additional services or days of inpatient care. Given the payment incentive to discharge "sicker and quicker" (Sager et al. 1989), many hospitals formed their own SNFs as a potential discharge location. At that time, Medicare paid SNFs on a cost-based basis. Relative to freestanding SNFs, hospital-based SNFs had higher costs per day and shorter length-of-stay. Hospitals claimed this was due to a more complex case-mix, while freestanding SNFs suggested it was due to accounting practices and unnecessary staffing costs. The number of hospital-based SNFs peaked in 1998 with 2,173 facilities nationwide (or 13.83\% of all SNFs). In 1998, Medicare adopted a PPS system for SNFs that imposed a uniform payment system on freestanding and hospital-based SNFs that did not recognize potential cost differences across the two settings other than those related to case-mix, area wages, and urban or rural location. Following the SNF PPS, many hospitals closed their SNFs (Rahman, Zinn, and Mor 2013c). By 2014, only about 800 SNFs (or 5\% of all SNFs) in the U.S. were hospital-based.

Answering the research question of the effect of SNF ownership on outcomes and costs is complicated by selection. Clearly, whether a hospital discharges a patient to its' own SNF is not random. Prior research has suggested that good candidates for faster recovery and discharge to the community are preferentially selected into hospital-based SNFs (Stearns et al. 2006). Thus, simple comparisons of discharge outcomes across hospital-based and freestanding SNFs, controlling for observable characteristics, will not yield causal estimates of the effect of SNF hospital-based status on discharge outcomes. To address this issue, we instrument for choice of a hospital-based SNF using differential distance from the patient's home to the nearest hospital with and without a SNF. Because distance is important towards predicting hospital choice and an individual chooses where to live without regard as to whether nearby hospitals own SNFs, the identifying assumption is that the instrument will be correlated with selection of a hospital with a 
SNF but independent of patient-specific health issues that would determine selection. With this instrument, we mimic randomization of residents into hospital-based SNFs when estimating the effects of hospital-based status on SNF discharge outcomes.

Using national Minimum Data Set assessments linked with Medicare claims, we study a national cohort of residents who were newly admitted to SNFs from a hospital in 2009. After instrumenting for hospital-based status, we found that hospital-based SNF patients spent 5.7

fewer days in a SNF relative to patients discharged to free-standing SNFs and 4.8 more days min the community without home health services.

\section{Conceptual Framework and Related Research}

\subsection{Conceptual Framework}

This conceptual framework explains the economics behind three choices central to our empirical analysis of SNF quality of care for patients who enter a SNF upon hospital discharge. First, the hospital chooses whether or not to have a hospital-based SNF. Second, after falling ill or needing treatment, the patient chooses the hospital, which may or may not have a hospitalbased SNF. Third, upon discharge the patient (in consultation with clinicians or discharge coordinators) chooses which SNF to enter. These three choices, which are made with an eye to quality of care, make it impossible to run simple ordinary least squares regression to identify the causal effect of being in a hospital-based SNF on quality of care. Fortunately, our conceptual framework also reveals a valid instrumental variable. We discuss each choice in turn.

Hospitals choose whether to have a hospital-based SNF or not, based on the expected profit from owning a hospital-based SNF compared to not owning one. A hospital then chooses 
to have a hospital-based SNF if the following expression comparing the expected present discounted difference between revenues and costs holds.

$$
\mathrm{E}[\text { Revenue - Costs } \mid \text { Hospital-based SNF }]>\mathrm{E}[\text { Revenue - Costs } \mid \text { no SNF }]
$$

This simple framework helps explain which types of hospitals are more likely to own a hospitalbased SNF and how this choice is endogenous with quality.

The main costs of running a nursing home are capital, labor, administrative overhead (including IT), and other input costs. Hospitals may have a lower cost of capital for raising money to build or expand, or may face higher costs if land prices near the hospital are higher than in more suburban or rural settings where nursing homes are typically located. Average labor costs per filled bed could be lower in a hospital-based SNF if nurses can be redeployed easily between the hospital and the SNF. Average costs can be lower in a vertically integrated hospital-based SNF that shares fixed costs of overhead or purchasing supplies. In sum, larger hospitals are more likely to have a hospital-based SNF than smaller hospitals.

On the revenue side, there are some clear advantages and disadvantages to having a hospital-based SNF. The fixed cost of running a SNF means that a hospital would need a sufficiently large number of discharges to make it likely that the SNF would be at, or near, capacity most of the time. A small hospital with few Medicare discharges would have higher variability in the occupancy rate, leading to lower average revenue per bed.

Hospitals with a hospital-based SNF have reasons to selectively steer certain patients to remain in the hospital system. Given that Medicare pays the same daily rate for all for SNF postacute patients in a given resource utilization group (RUG), profitability across patients differs 
entirely by their costs. Within a given RUG, hospitals then have an incentive to select the least costly patients to be admitted to their own SNF and to send the more expensive patients to freestanding facilities. Over the last few years, CMS has given hospitals an additional reason to select particular patients for care in the hospital-based SNF— the hospital readmissions reduction program and the hospital value-based purchasing programs penalize hospitals that have high readmission rates and high 30-day episode spending. If a hospital believes that a patient is at risk for readmission or high post-discharge expenses, the hospital can monitor that patient's progress better when admitted to their own SNF.

Both of these patient selection issues cause endogeneity in a simple regression to predict quality outcomes based on whether a patient enters a hospital-based or a freestanding SNF. Patients selected to enter a hospital-based SNF due to expected low costs will have better health status that is unobservable to the econometrician, causing omitted variable bias. Patients selected to enter a hospital-based SNF due to concerns about mortality and risk of readmission cause bias due to reverse causality.

Turning to the patient's choice of hospital, this complex function depends on things including referral patterns, past experience, expectations of quality of care, patient health status, and distance. Similarly, the choice of which SNF to go to (for patients discharged to a SNF) depends on things including whether the hospital has a hospital-based SNF, referral patterns, past experience, expectations of quality of care, patient health status, and distance. All else equal, patients prefer to travel a shorter distance to receive medical care. Therefore, we expect that some function of distance will strongly predict both the choice of hospital and the choice of whether the patient is admitted to a hospital-based SNF, and that distance is unrelated to the endogenous parts of the choices including the patient's unobserved health status. In short, some 
function of distance will be a strong and valid instrumental variable for whether the patient is admitted to a hospital-based SNF upon discharge.

This conceptual framework also provides an economic justification for why hospitalbased SNFs may provide better quality of care than freestanding SNFs, thus motivating our central research question. Hospital-based SNFs may produce better discharge outcomes relative to freestanding SNFs due to both economies of joint production and specialization. In this case, joint production leads to better communication between hospital and nursing home staff in part through a shared health IT system. Given that CMS pay-for-performance programs now penalize hospitals with high mortality, high readmissions rates, and high episode payments, hospitals with a hospital-based SNF can better align incentives in a vertically integrated system. For example, if a patient at risk of readmission is kept in a hospital-based SNF, then the hospital can develop a care plan appropriate for preventing avoidable readmissions.

The second pathway through which hospital-based SNFs may affect outcomes is via specialization (Norton 2000). In most freestanding SNFs, post-acute care SNF patients constitute a relatively small proportion of total residents. The majority of nursing home residents are long-stay, chronically ill individuals covered by Medicaid. Previous research has suggested that some residents do better when nursing homes specialize in treating a narrow range of patients (Grabowski et al. 2010; Grabowski, Gruber, and Angelelli 2008; Konetzka et al. 2006). That is, when high- and low-margin payer groups receive care alongside one another, outcomes for higher-margin patients typically decline, while outcomes for lower-margin patients typically increase. We hypothesize that hospital-based SNFs will be more specialized in care for highmargin patients because - unlike most freestanding SNFs - they do not have to cross-subsidize lower-margin patients covered by Medicaid. 
Our conceptual framework argues that hospital-based SNFs are likely to have higher quality of care than freestanding SNFs, that a simple regression will produce biased estimates of the causal effect of type of SNF on discharge outcomes, and that a function of distance will be a valid instrumental variable.

\subsection{Previous Literature}

Few studies have specifically focused on the relationship between hospital-based status and SNF quality of care, yet most SNF quality studies control for hospital-based status as a covariate in the regression model (for reviews, see Grabowski and Norton 2012; Norton 2000). A large literature has focused on the related issue of cost and case-mix differences across freestanding and hospital-based SNFs. In a review of the early pre-PPS SNF evidence, Wiener and colleagues (1986) concluded that hospital-based SNF patients were twice as costly per day as freestanding SNF patients but case-mix differences explained less than half of the cost differential. Using an endogenous switching model with data from the mid-1990s, Pizer and colleagues (2002) concluded that the entire cost differential is attributable to setting effects and case-mix selection plays a negligible role. In an analysis of 1999 data following the adoption of the SNF PPS, hospital-based SNFs were found to have higher per diem costs for nursing and non-therapy ancillary services, while freestanding SNFs had higher average costs for rehabilitation services (Liu and Black 2003).

In terms of research focusing on outcomes, Liu and Black (2003) examined unadjusted discharge outcomes. Hospital-based SNFs had lower length-of-stay (13 days versus 27 days), mortality ( $4 \%$ versus $7 \%$ ), and hospital readmission (23\% versus $28 \%)$. Whether these outcomes are related to case-mix or differences in care is impossible to tease out from this study. Rahman 
and colleagues (2013c) found local markets with greater closure of hospital-based SNFs between 1999 and 2006 experienced increased 30-day hospital readmissions. Stearns and colleagues (2006) used propensity stratification to compare patient outcomes across hospital-based and freestanding SNFs. The authors found that patients admitted to hospital-based SNFs had 16.7\% shorter stays, a 7.7\% greater likelihood of home discharge within 30 days, and 2.3\% fewer preventable 30-day hospital readmissions. As the authors acknowledge about their study, "(o)ne limitation of our analysis is that unobserved selection still may explain the remaining differences in outcomes for patients of hospital-based SNFs. A natural approach to investigate this issue is to use instrumental variables (IV) models" (page 620).

We were only able to identify one previous study that examined patient outcomes in hospital-based SNFs using an IV approach. Specifically, David and colleagues (2013) instrument for a particular hospital owning a SNF by using the rate of SNF ownership by other hospitals in the same market. Using this approach, the authors found lower 60-day hospital readmission rates for patients discharged to a SNF owned by that hospital.

\section{Data and Study Sample}

\subsection{Data sets}

For this study we need detailed data on individuals, including where they resided on each day following discharge, when they died, and total Medicare reimbursement on all covered services up to 180 days post discharge. We used several sources of data in this study to obtain SNF and individual characteristics including the Minimum Data Set (MDS), Medicare claims, the Medicare denominator file, SNF provider data, zip code level population characteristics based on census 2000, and data from the American Hospital Association (AHA). 
The MDS assessment forms are completed for all residents in certified SNFs upon admission and then at least quarterly thereafter. The MDS instrument has numerous data elements and includes summary measures of cognitive and physical functioning, continence, pain, mood state, diagnoses, health conditions, mortality risk, special treatments, and medication use. Numerous reliability and validity studies reveal that most MDS items achieve an intra-class correlation of 0.6 (Abt Associates Inc. 2002; Hawes et al. 1995; Mor 2004; Mor et al. 2011; Morris et al. 1990; Phillips et al. 1997).

The Medicare Standard Analytic File includes all claims related to inpatient, skilled nursing facility care, home health, and hospice services for Medicare fee-for-service enrollees. All Part A claims (inpatient, SNF) include dates of service and up to 25 diagnoses. The Medicare enrollment file identifies individuals enrolled in Medicare within a given year and includes demographic data, survival status, residential zip code, and program eligibility information for Parts A, B and D, Medicare Advantage (managed care), and Medicaid.

The Online Survey Certification and Reporting (OSCAR) System is a compilation of data elements collected by surveyors during inspection surveys conducted at nursing facilities. Surveys are conducted at least once during every 15 -month period to certify participation in the Medicare and Medicaid programs. The database includes organizational characteristics such as the number of beds, ownership, and chain membership and aggregate patient characteristics. The AHA data are a census of United States hospitals based on the AHA Annual Survey of Hospitals. The database includes different structural characteristics of hospitals. In this study, we used AHA data from the 2007 survey.

\subsection{Study cohort}


Applying the Residential History File methodology (Intrator et al. 2011), which concatenates MDS assessment and Medicare claims into individual beneficiary trajectories, we identified all Medicare fee-for-service (FFS) beneficiaries who were discharged directly from an acute general hospital to a SNF for post-acute care in 2009. We excluded patients with any SNF residence history in one year prior to admission because they would be frailer than post-acute care patients from the community. We found 1.2 million individuals who were discharged from hospital to SNFs during the study period who did not have a prior nursing home stay. We dropped about 24 percent of the individuals who did not reside in the 48 contiguous states, were not discharged from an acute general hospital, or were missing relevant hospital or SNF identification. Our final sample consisted of 827,541 Medicare FFS beneficiaries discharged from 3,173 acute care hospitals to 14,374 SNFs.

\subsection{Outcome Variables}

To determine the post-acute outcomes, we followed each patient for 30 or 180 days after their SNF admission by concatenating Medicare enrollment, Medicare claims claims and MDS using the residential history algorithm (Intrator et al. 2011). On any given day, an individual can be in one of the following five settings: death, hospital, SNF, home with home health care and home without home health care. We constructed five outcome variables representing the number of days in different settings such that summation of these variables for any individual is 180 . The mean number of days in different settings has been reported in Table 2 . The mean number of days in a nursing home is about 51 days. Of note, the number of days in a particular setting may involve residence with different providers. Patients are sometimes transferred between hospital based and free standing SNFs. About $16 \%$ of our patients who were initially discharged to a hospital based SNF later stayed a free-standing SNF (with 11\% direct transfer). Transfers from 
free-standing SNF to hospital based SNF is very rare. We also ran a related analysis examining the likelihood of these five outcomes on a day-by-day basis.

Of note, these five categories of outcomes show a patient's location on a given day, but they do not necessarily identify the intensity of services used by the patient on that day. As such, we also examined specific types of care use over a one-month and six-month discharge period. The 30-day outcomes align with the incentives in the CMS pay-for-performance programs, while the 180-day outcomes give a longer-run perspective. More specifically, we examined aggregated Medicare spending as well as Medicare spending on inpatient, SNF, and home health services during these time windows. As shown in Table 2, Medicare spent about $\$ 8,000$ on acute hospital care, $\$ 14,000$ on SNF care and $\$ 2,500$ on home health care in the six months following SNF admission for an average patient. These reimbursements do not necessarily correspond to the number of days in a setting because some services are paid by the patient (out-of-pocket) or by other insurers (including Medicaid). We also examined death (0/1) and any hospital readmission. $22 \%$ of the patients discharged to a SNF died within six months, while about half of all the patients experienced a hospital readmission within six months following SNF admission.

\subsection{Main explanatory variable}

Our main explanatory variable is an indicator of whether the treatment SNF is hospital based or not. We identified the hospital affiliation of a SNF from OSCAR data which also provides the identification number of the affiliated hospital. We did not use AHA data to identify hospitals with SNF because AHA appears to under-count the number of hospitals with hospitalbased SNF and do not provide the identification of the affiliated SNF.

\subsection{Control variables}


We included control variables from four different sources. We obtained age, gender, race, and Medicaid eligibility from the Medicare enrollment file. We merged zip code characteristics based on 2000 census using patient's residential zip code from Medicare enrollment data. These zip code level variables are poverty rate among elderly population, physical and mental disability rate, share of Medicare beneficiaries enrolled in Medicare Advantage, population density and racial composition of elderly population.

From the index hospitalization claims prior to SNF admission, we included Elixhauser (Elixhauser et al. 1998) and Deyo (Deyo, Cherkin, and Ciol 1992) co-morbidity indexes, hospital length of stay, and the number of intensive care unit (ICU) days during the hospitalization. We used home health claims to construct an indicator of home health utilization before the index hospital stay. Other clinical characteristics were obtained from the MDS and include indicators for common diagnoses (e.g., diabetes, serious mental illness etc.), the number of medications taken in the last seven days, the Morris late loss ADL scale (Morris, Fries, and Morris 1999), the cognitive performance scale (Morris et al. 1994), the resource utilization group (5.12) (Fries and Cooney 1985; Fries et al. 1994) and the Changes in Health, End-stage disease, Signs and Symptoms (CHESS) score (Hirdes, Frijters, and Teare 2003). The control variables are summarized for the full sample (see Table 3).

\section{Methods}

\subsection{Empirical specification}

This paper estimates the relationship between patient outcomes (number of days in five mutually exclusive and exhaustive states, and Medicare payments) and SNF hospital-based status, controlling for patient factors and hospital referral region fixed effects. 


$$
\text { Outcome }_{\text {in }}=\beta_{0}+\beta_{1} H B_{n}+\text { Patient }_{i} \gamma+\theta_{H R R}+u_{\text {in }}
$$

where Outcome $e_{\text {in }}$ is the outcome for patient $i$ discharged to nursing $n . H B_{n}$ indicates whether the treating SNF $n$ is hospital based or not. Patient $t_{i}$ is a vector of the individual's demographic, clinical and residential zip-code characteristics. $\theta_{H R R}$ are hospital referral region fixed effects. We expect that the coefficients on $\beta_{1}$ to differ for each outcome.

\subsection{Instrument}

The differential selection of individuals into hospital-based SNFs may reflect both demand and supply side factors. On the demand side, this selection may relate to the value that certain individuals place in receiving services from a hospital with their own SNF. In other words, patients in worse health have the most to gain from vertically integrated SNF care. On the supply side, hospitals that own their own SNF can siphon off those most desirable patients likely to benefit from SNF care. Although Medicare SNF payment is case-mix adjusted, the system uses a relatively narrow set of patient conditions in adjusting payments.

If unobserved health is similarly correlated with SNF choice and quality, the assumption underlying the linear regression model is violated. However, we can still generate a consistent estimate of the effect of hospital-based status on quality if we can identify a variable DD that is correlated with hospital-based status but not the error term $\left(u_{i n}\right)$ in the quality equation. Given DD, we can calculate an IV estimate of the effect of hospital-based status on quality.

We assume that differential distance between the nearest hospital with and without a SNF will strongly predict entry into a hospital-based SNF. That is, individuals that live closer to a hospital with a SNF are more likely to be admitted to that hospital, and then conditional on being admitted to that hospital, they are more likely receive care in a hospital-based SNF. Our data suggest that $42 \%$ of patients discharged from a hospital with a SNF were admitted to a hospital- 
based SNF versus $2 \%$ of patients discharged from a hospital without a SNF. A large health services literature establishes the importance of distance in the choice of provider (e.g., Brooks et al. 2006; Hirth et al. 2003; McClellan, McNeil, and Newhouse 1994; Rahman and Foster 2015; Rahman et al. 2014; Tan et al. 2012). Indeed, in our study, the median distance traveled to a hospital was 11.5 kilometers (or 7.1 miles). In the study that most closely mirrors the distancebased instrument used in this study, Grabowski and colleagues (2013) found the relative proximity to nonprofit and for-profit SNFs to be a strong predictor of the type of SNF chosen. One important difference in this paper is that we use differential distance to the nearest hospital with and without a SNF (rather than the differential distance to the nearest SNFs). The use of the hospital distance is warranted in this study because we are leveraging hospitals increased likelihood of discharging to a hospital-owned SNF.

We also expect differential distance to be uncorrelated with unobserved factors that may influence outcomes. We assert that individuals choose a place of residence without regard to the proximity of hospitals with and without a SNF. This accords with common sense, and does not preclude people from making housing choices on the basis of proximity to a hospital. The relatively low rate of elderly migration supports this assumption (U.S. Census Bureau 2003). As such, we hypothesize that the differential distance measure is predetermined for potential SNF patients and unrelated to unobserved SNF outcomes. In the next section, we report a falsification test to validate this assumption. We also report mean characteristics by value of the differential distance (above or below median) in a balance table (see Table 3).

To construct a differential distance (DD) measure for SNF patients, we calculated the distance using the great circle formula from the centroid of the resident's zip code prior to hospital admission, as reported in Medicare enrollment data, to the exact geo-address of the 
nearest hospital with and without a SNF based on the latitude and longitude of the respective facilities. We used natural log of distance between zip code and the nearest hospital with and without SNF. The differential measure was then calculated as the natural log of distance to the nearest hospital with a SNF minus natural log of the distance to the nearest hospital without a SNF. In other words, the measure's interpretation is how much farther the patient would have to travel to be admitted to the nearest hospital with a SNF. A negative value on this measure indicates that the nearest hospital is one with a SNF. Therefore, we expect a negative coefficient on differential distance in the first-stage results.

Our instrument is strong and valid. First, the instrument is balanced with respect to the covariates (see Table 3). Our analyses are based on comparisons of where patients lived relative to the closest hospitals with and without a SNF. Thus, we split the sample by whether the instrument was above or below the median to check for balance in the observable characteristics. Although many of the paired comparisons were statistically significantly different at the 5 percent level due to the extraordinarily large sample size, the patient characteristics were virtually identical across the two samples. The fact that none of these measured patients' demographic and clinical characteristics are correlated with the instrument makes it hard to argue that there are obvious sources of confounders that would make the instrument invalid.

Second, the instrument is a strong predictor of the endogenous variable, hospital-based SNF status, in the first stage (see Table 4). Column 1 reports the first stage where the IV is the linear differential distance i.e., distance (in kilometers) of the nearest hospital with a SNF minus the distance to the nearest hospital without a SNF. The first-stage estimates suggest that a one kilometer increase in the differential distance between then nearest hospitals with and without a SNF led to a 0.2 percentage point decrease in the likelihood of being admitted to a hospital-based 
SNF. The second column reports the first stage where the IV is the difference in natural log distance between the nearest hospital with and without a SNF (i.e., the natural log of the ratio of distances). We used the log version of differential distance for our main analysis because of it is less susceptible to the influence of extreme outliers in differential distance. The $t$-statistic based on robust standard error is 20.06 , meaning that the $F$-statistic is over 400 . The partial $R$-squared is 0.057 . This is after controlling for hospital referral region fixed effects, so that the prediction is based entirely on within-referral region correlations. Clearly, the instrument strongly predicts the patient's choice of a hospital-based SNF.

As a final specification check, we conducted a falsification test of our instrument, which we draw from the identification strategy of an unrelated recent study. Doyle (2011) used people treated in Florida that did not reside there ("vacationers") as a means of addressing selection of individuals into high and low cost areas in studying the relationship between spending and health care outcomes. We borrow from this idea by examining individuals who enter a hospital far away from their primary residence. The concentration of hospitals with SNFs around their primary residence should not affect entry into a hospital-based SNF for those individuals who enter a SNF near a family member living elsewhere or get sick or need surgery while on vacation. For this sub-sample of "vacationers," the first stage should be close to zero. If it is negative and large, then we could conclude that where individuals live relative to the nearest hospitals with and without SNFs is correlated with unmeasured quality (which would violate the assumption underlying a valid instrument).

In conducting this falsification test, we excluded individuals entering hospital less than $100 \mathrm{~km}$ and alternately define this vacationer sub-sample as individuals entering a hospital over $100 \mathrm{~km}(\mathrm{~N}=48,287$ or $5.8 \%$ of full sample), $200 \mathrm{~km}(\mathrm{~N}=27,449$ or $3.3 \%$ of full sample $)$ or 500 
$\mathrm{km}(\mathrm{N}=17,996$ or $2.2 \%$ of full sample) away from their primary residence. The results suggest a weak first-stage estimate of the DD instrument for the vacationer sub-samples (see columns 3-5 in Table 4). When we use a cutoff of 100 kilometers to define the vacationer sub-sample, the first-stage estimate is roughly $23 \%$ as large as the result from the full sample. When we use a cutoff of 200 kilometers, the effect is about $7 \%$ as large as the full sample. When we use a cutoff of 500 kilometers, the first-stage estimate becomes statistically insignificant and it is $3.2 \%$ as large as the result from the full sample. This gradual decline in the first stage relationship suggests that we can say with some precision that this falsification check does not support the idea that an individual's place of residence relative to the nearest hospitals with and without SNFs is strongly correlated with other (unmeasured) factors that predict quality of care.

We used the typical fixed effect 2SLS estimation (using xtivreg2 command in Stata) to estimate equation (1). All the test statistics are based on robust standard errors.

\section{Results}

\subsection{Primary Findings}

The estimates of the effect of hospital-based SNF status on the days spent in different discharge settings are presented in Table 5. Once again, we examine the first 180 days following discharge of the individual from the hospital. In the table, we present both the standard model that treats hospital-based status as exogenous (OLS model, row 2-3), and the IV model that treats hospital-based status as endogenous (row 4). We show the OLS and IV results both with HRR fixed effects. For the majority of outcomes, the results are quite different across the two models.

In the OLS model treating hospital-based status as exogenous, we obtain results similar to earlier estimates in the literature. That is, we find that hospital-based SNF patients spend 14 
fewer days in a SNF over the 180 day post-discharge period and 8.8 more days in the community without home health care and 4.1 days with home health care. We find very slight increases in mortality (0.952 days) and any hospitalization (0.258 days). When we included HRR fixed effects in the OLS model, the results generally became even larger, suggesting fewer days in SNF and more days in the community. The fact that the within-HRR effects are so large is consistent with the idea that hospitals are differentially selecting patients that are good candidates for a quick discharge into their own SNFs.

When we account for endogenous ownership in the IV models, we obtain results of a much more plausible magnitude. Specifically, patients admitted to hospital-based SNFs spend 5.7 days less in a SNF relative to patients discharged to free-standing SNFs and 4.8 days more in the community without home health services. When you put these results together, freestanding SNF patients spend relatively more time in a health care institution and less time in community in the 180 days following their original hospital discharge than hospital-based SNF patients.

Figure 2 presents the daily distribution of individuals in the study cohort as they transitioned through different locations of care following their first-time admission to hospitalbased and freestanding SNFs. Differences in the likelihood of residing in a given setting emerge quickly. On any given day, free-standing SNF patients were more likely to stay in nursing homes and less likely to be discharged back to the community without receiving home health care, as compared to hospital-based SNF patients. We observed about six more home health care days for hospital-based SNF patients (see row 1, Table 5). According to panel D of figure 2, all these extra home health days were during the first two months following discharge.

In order to examine the distribution of discharge outcomes on a day-to-day basis, we estimated 180 daily linear probability models for each competing outcome using HRR fixed 
effects and treating an admission to a hospital-based SNF as endogenous. Ideally, we should have estimated multinomial outcome model for each day and calculated the marginal effects of admission to hospital based SNF for each competing outcome. However, the presence of the HRR fixed effect made the estimation procedure computationally very intensive. We plotted the estimated effect of admission to hospital-based SNF on competing outcomes with respect to days in Figure 3. We found differential impacts of hospital-based status over the 180-day window. For hospital-based SNF patients, the likelihood of home health care use was higher initially while SNF use was lower. Around day 20, the difference in home health care and SNF use reached its' maximum. The fact that Medicare copayments begin at day 20 may be related to the differential utilization across freestanding and hospital-based SNFs. Discharge home was higher for hospitalbased SNF patients during the first three months following discharge. Patients in hospital-based SNFs were less likely to go back to hospital in the first week following discharge and then the effect becomes statistically insignificant. This effect of fewer immediate bounce backs to the hospital is consistent with other studies (Rahman et al. 2013a; Rahman et al. 2013c). There no significant impact on mortality. All the effects were statistically insignificant after 100 days of SNF admission, implying that there was no permanent effect of treatment in hospital based SNF as we observed with the unadjusted gap in Figure 2. This figure also suggests our estimated effects are not picking up any permanent unobserved patient characteristics that are associated with hospital based SNF selection and outcomes.

We also considered the impact of being treated in a hospital-based SNF on Medicare spending in the first month and six months following hospital discharge (see Tables 6 and 7). In the unadjusted comparison, 30-day Medicare spending following discharge was $\$ 3,432$ lower for individuals discharged from a hospital-based SNF. When we controlled for the covariates and 
included HRR fixed effects, the difference fell to $\$ 2,456$. When we ran an IV model, the Medicare savings was $\$ 2,882$. In these IV models, we observed a small and statistically insignificant impact on mortality, suggesting the savings were not a result of censoring due to mortality. The main source of savings was lower SNF spending, with some additional savings from inpatient care and some additional spending on home health care. Comparing Table 6 with Table 7, the only savings by month six was from lower SNF payments.

\subsection{Specification Checks}

In order to examine the robustness of our primary model specification, we ran a series of alternate models (see Table 9). We first experimented with an alternate form of the DD instrument in which we used a linear distance instead of natural log transformed distance and a binary instrument (above/below DD median) to take account of skewed values. Patients who live in areas with no hospitals with SNFs will have large differential distance values using the linear distance instrument. On the other hand, the binary version of the DD instrument will suppress the role of large absolute values. The estimated effects using linear differential distance are much larger. However our baseline results were similar to the results generated with a binary instrument, suggesting our results are not being driven by outliers of the standard instrument.

Another potential issue is that the effects we observed might be predominantly concentrated in certain markets. As shown in table 1, hospital based SNFs are more prevalent in rural areas i.e. $30 \%$ of all free-standing SNFs and $50 \%$ of all hospital based SNFs are located in rural counties. When we estimated our models conditional on urban and rural markets, we found that the results for rural markets were relatively similar to the overall results. We also investigated whether the magnitude of our result varied based on the competitiveness of the local 
market. Using the county to approximate the market, we split the sample based on the median Herfindahl value. We found quite similar effects in both types of markets.

Another potential check on selection is to focus our results on only those individuals without a planned hospitalization. For example, a patient with a scheduled knee replacement surgery will be able to weigh potential rehabilitation options across hospitals. However, for an individual with an unplanned hospitalization, they will not be able to consider issues related to whether the hospital has their own SNF. To investigate this issue, we examined hip fracture, acute myocardial infarction (AMI), and stroke patients. The pattern of all three diagnosis results was similar to the overall population, although both groups had even higher SNF utilization among hospital-based SNF patients.

One final concern is that hospital quality of care could be higher in hospitals with a hospital-based SNF than in hospitals without one, and that higher quality of inpatient care could spuriously cause our results. Although this is a valid concern, with Table 3 showing insignificant differences in treating hospital characteristics between patients with lower and higher values of the IV, our methods protect against this kind of bias. Our models control for HRR fixed effects, sweeping away crude geographic differences. The local average treatment effect of the IV analysis is that of the marginal patient whose choice of SNF is determined by happenstance of home location, not those patients who chose to go to the hospital because of perceived differences in quality of care. If inpatient quality of care was so important, we would expect to see significant differences in mortality and readmission rates in the first few days post discharge, yet we do not see such differences. 
In summary, the specification checks generally suggest our primary findings are robust, although we did observe some heterogeneity across different markets (urban/rural, more/less competitive markets).

\section{Conclusion}

The research question of whether hospital-based SNFs produce better outcomes at lower Medicare payments is important given recent Medicare policies that hold health care systems and payers accountable for post-hospital discharge outcomes and spending. Our conceptual framework provides economic reasons for why hospital-based SNFs may be different (and better) than freestanding SNFs. On the other hand, it also suggests that simple correlations will yield biased results due to selection. Our instrumental variable is strong and valid. The instrumental variables results then give consistent estimates of the causal effect of going to a hospital-based SNF (compared to a freestanding SNF). The 30-day results are most policy relevant while the 180-day results provide a better understanding of the long-run effects.

Our paper is suggestive of the idea that hospital-based SNFs generate some savings for Medicare over the 6-month hospital discharge period. These savings are largely achieved via lower SNF spending. As health care systems and payers increasingly take on risk for Medicare hospital discharge episodes, these results provide some support for vertical integration of hospitals and SNFs. Hospitals are faced with a "make-or-buy" decision in terms of partnering with SNFs in that they can own their own SNF or they can establish relationships with freestanding SNFs. ACOs and hospital networks are currently developing strategies to develop networks of SNF partners (Lage et al. 2015; Maly et al. 2012). Previous research suggests that when hospitals concentrate their discharges in a particular SNF, they will have lower 
readmission rates from this SNF (Rahman et al. 2013b; Schoenfeld et al. 2016). From a policy perspective, the key issue will be whether the potential additional savings we have observed in this study are enough to justify the increased costs of owning a SNF under global and accountable payment systems.

We have found that discharge to a hospital-based SNF leads to more rapid community discharge with a lower likelihood of hospital readmission. From a consumer perspective, potential value exists in seeking care at hospitals that own their own SNFs. This issue could be reported on Hospital Compare as a potential signal of quality for elective procedures that could require post-acute care (e.g., lower extremity joint replacement).

A potential limitation of this study is that it is based on SNF admissions in 2009. Though the data are about six years old, the effect of more integrated acute and post-acute care on patient's discharge outcomes is not likely to change over time. Additionally, we must be careful in over-interpreting these results. The marginal patient in our model is someone who received treatment in a hospital-based SNF due to their prior residence being differentially closer to a hospital with a SNF. The experience of these individuals may not generalize to the universe of SNF patients. However, at least for these patients at the margin, we do observe some potential savings associated with hospital-based SNFs via lower SNF utilization.

In sum, we found that hospital-based SNF patients spent more days in the community and fewer days in the SNF in the 180 days following their original hospital discharge with no significant effect on mortality or hospital readmission. Medicare spent almost \$2,900 less on a hospital-based SNF patient in the 30 days following their original hospital discharge. As health care systems and payers increasingly take on risk for Medicare hospital discharge episodes, these findings provide some support for vertical integration of hospitals and SNFs. 


\section{Acknowledgements}

We would like to thank Christian Brostrup-Jensen and other members of CGHCR for helping us with data retrieval. We are grateful for comments by seminar participants at the London School of Economics, ASHEcon, CIRANO (Montreal), Tulane University and Texas A\&M University. 


\section{References}

Abt Associates Inc. 2002. "MegaQI Covariate Analysis and Recommendations: Identification and Evaluation of Existing Quality Indicators That Are Appropriate for Use in Long-Term Care Settings.” Prepared by D. Kidder, M. Rennison, H. Goldberg, D. Warner, B. Bell, L. Hadden, J. Morris, R. Jones, \& V. Mor, for Centers for Medicare and Medicaid Services (Contract No. 50095-0062 TO \#4).

Ackerly, D. C. and D. C. Grabowski. 2014. "Post-acute care reform--beyond the ACA." The New England journal of medicine 370(8): 689-91.

Brooks, J. M., C. P. Irwin, L. G. Hunsicker, M. J. Flanigan, E. A. Chrischilles, and J. F. Pendergast. 2006. "Effect of dialysis center profit-status on patient survival: a comparison of risk-adjustment and instrumental variable approaches." Health Serv Res 41(6): 2267-89.

David, G., E. Rawley, and D. Polsky. 2013. "Integration and Task Allocation: Evidence from Patient Care." Journal of Economics and Management Strategy 22(3): 617-39.

Deyo, R. A., D. C. Cherkin, and M. A. Ciol. 1992. "Adapting a clinical comorbidity index for use with ICD-9-CM administrative databases." J Clin Epidemiol 45(6): 613-9.

Doyle, J. J. 2011. "Returns to Local-Area Healthcare Spending: Evidence from Health Shocks to Patients Far From Home.” American Economic Journal: Applied Economics 3(3): 221-43.

Elixhauser, A., C. Steiner, D. R. Harris, and R. M. Coffey. 1998. "Comorbidity measures for use with administrative data." Med Care 36(1): 8-27.

Fries, B. E. and L. M. Cooney, Jr. 1985. "Resource utilization groups. A patient classification system for long-term care." Med Care 23(2): 110-22. 
Fries, B. E., D. P. Schneider, W. J. Foley, M. Gavazzi, R. Burke, and E. Cornelius. 1994.

"Refining a case-mix measure for nursing homes: Resource Utilization Groups (RUG-III)." Med Care 32(7): 668-85.

Grabowski, D. C., Z. Feng, R. Hirth, M. Rahman, and V. Mor. 2013. "Effect of nursing home ownership on the quality of post-acute care: an instrumental variables approach." J Health Econ 32(1): 12-21.

Grabowski, D. C., Z. Feng, O. Intrator, and V. Mor. 2010. "Medicaid bed-hold policy and Medicare skilled nursing facility rehospitalizations." Health Services Research 45(6 Pt 2): 196380.

Grabowski, D. C., J. Gruber, and J. J. Angelelli. 2008. "Nursing Home Quality as a Common Good." Review of Economics and Statistics 90(4): 754-64.

Grabowski, D. C. and E. C. Norton. 2012. “Nursing Home Quality of Care.” In The Elgar Companion to Health Economics, Second Edition, edited by A. M. Jones, pp. 307-17. Cheltenham, UK: Edward Elgar Publishing, Inc. Hawes, C., J. N. Morris, C. D. Phillips, V. Mor, B. E. Fries, and S. Nonemaker. 1995. "Reliability estimates for the Minimum Data Set for nursing home resident assessment and care screening (MDS)." Gerontologist 35(2): 172-8.

Hirdes, J. P., D. H. Frijters, and G. F. Teare. 2003. "The MDS-CHESS scale: a new measure to predict mortality in institutionalized older people." J Am Geriatr Soc 51(1): 96-100.

Hirth, R. A., M. E. Chernew, M. N. Turenne, M. V. Pauly, S. M. Orzol, and P. J. Held. 2003. “Chronic illness, treatment choice and workforce participation." Int J Health Care Finance Econ 3(3): 167-81. 
Intrator, O., J. Hiris, K. Berg, S. C. Miller, and V. Mor. 2011. "The residential history file: studying nursing home residents' long-term care histories(*)." Health Serv Res 46(1 Pt 1): 12037.

Konetzka, R. T., E. C. Norton, P. D. Sloane, K. E. Kilpatrick, and S. C. Stearns. 2006. "Medicare prospective payment and quality of care for long-stay nursing facility residents." Medical Care 44(3): 270-6.

Lage, D. E., D. Rusinak, D. Carr, D. C. Grabowski, and D. C. Ackerly. 2015. "Creating a network of high-quality skilled nursing facilities: preliminary data on the postacute care quality improvement experiences of an accountable care organization.” J Am Geriatr Soc 63(4): 804-8. Liu, K. and K. J. Black. 2003. "Hospital-based and freestanding skilled nursing facilities: any cause for differential Medicare payments?" Inquiry : a journal of medical care organization, provision and financing 40(1): 94-104.

Maly, M. B., S. Lawrence, M. K. Jordan, W. J. Davies, M. J. Weiss, L. Deitrick, and D. SalasLopez. 2012. "Prioritizing partners across the continuum." J Am Med Dir Assoc 13(9): 811-6. McClellan, M., B. J. McNeil, and J. P. Newhouse. 1994. "Does more intensive treatment of acute myocardial infarction in the elderly reduce mortality? Analysis using instrumental variables." Jama 272(11): 859-66.

Mor, V. 2004. “A comprehensive clinical assessment tool to inform policy and practice: applications of the minimum data set." Medical care 42(4 Suppl): III50-9. Mor, V., O. Intrator, M. A. Unruh, and S. Cai. 2011. "Temporal and Geographic variation in the validity and internal consistency of the Nursing Home Resident Assessment Minimum Data Set 2.0." BMC health services research 11: 78. 
Morris, J. N., B. E. Fries, D. R. Mehr, C. Hawes, C. Phillips, V. Mor, and L. A. Lipsitz. 1994. “MDS Cognitive Performance Scale.” J Gerontol 49(4): M174-82.

Morris, J. N., B. E. Fries, and S. A. Morris. 1999. "Scaling ADLs within the MDS." J Gerontol A Biol Sci Med Sci 54(11): M546-53.

Morris, J. N., C. Hawes, B. E. Fries, C. D. Phillips, V. Mor, S. Katz, K. Murphy, M. L.

Drugovich, and A. S. Friedlob. 1990. "Designing the national resident assessment instrument for nursing homes." Gerontologist 30(3): 293-307.

Newhouse, J. P. G., A.;Graham,R.P.;McCoy,M.A.;Mancher,M;Kibria,A (Editors). 2013. "Interim Report of the Committee on Geographic Variation in Health Care Spending and Promotion of High-Value Health Care: Preliminary Committee Observations.” Washington,D.C.: The National Academies Press.

Norton, E. C. 2000. “Long-Term Care.” In Handbook of health Economics, edited by A. J. Culyer and J. P. Newhouse, pp. 955-94. Amsterdam: Elsevier Science, North-Holland.

Norton, E. C. and D. O. Staiger. 1994. "How Hospital Ownership Affects Access to Care of the Uninsured.” Rand Journal of Economics 25(1): 171-85.

Phillips, C. D., J. N. Morris, C. Hawes, B. E. Fries, V. Mor, M. Nennstiel, and V. Iannacchione. 1997. "Association of the Resident Assessment Instrument (RAI) with changes in function, cognition, and psychosocial status." J Am Geriatr Soc 45(8): 986-93.

Pizer, S. D., A. J. White, and C. White. 2002. "Why are hospital-based nursing homes so costly? Relative importance of acuity and treatment setting." Medical Care 40(5): 405-15.

Rahman, M. and A. D. Foster. 2015. "Racial segregation and quality of care disparity in US nursing homes." J Health Econ 39: 1-16. 
Rahman, M., A. D. Foster, D. C. Grabowski, J. S. Zinn, and V. Mor. 2013a. "Effect of hospitalSNF referral linkages on rehospitalization." Health Services Research 48(6 Pt 1): 1898-919.

Rahman, M., A. D. Foster, D. C. Grabowski, J. S. Zinn, and V. Mor. 2013b. "Effect of hospitalSNF referral linkages on rehospitalization.” Health Serv Res 48(6 Pt 1): 1898-919.

Rahman, M., D. C. Grabowski, P. L. Gozalo, K. S. Thomas, and V. Mor. 2014. "Are dual eligibles admitted to poorer quality skilled nursing facilities?" Health Serv Res 49(3): 798-817. Rahman, M., J. S. Zinn, and V. Mor. 2013c. "The impact of hospital-based skilled nursing facility closures on rehospitalizations." Health Serv Res 48(2 Pt 1): 499-518.

Sager, M. A., D. V. Easterling, D. A. Kindig, and O. W. Anderson. 1989. "Changes in the location of death after passage of Medicare's prospective payment system. A national study." $N$ Engl J Med 320(7): 433-9.

Schoenfeld, A. J., X. Zhang, D. C. Grabowski, V. Mor, J. S. Weissman, and M. Rahman. 2016. "Hospital-skilled nursing facility referral linkage reduces readmission rates among Medicare patients receiving major surgery." Surgery.

Stearns, S. C., K. Dalton, G. M. Holmes, and S. M. Seagrave. 2006. “Using propensity stratification to compare patient outcomes in hospital-based versus freestanding skilled-nursing facilities." Med Care Res Rev 63(5): 599-622.

Tan, H. J., E. C. Norton, Z. Ye, K. S. Hafez, J. L. Gore, and D. C. Miller. 2012. "Long-term survival following partial vs radical nephrectomy among older patients with early-stage kidney cancer." JAMA 307(15): 1629-35.

U.S. Census Bureau. 2003. "Internal Migration of the Older Population: 1995-2000.” Census 2000 Special Reports. U.S. Department of Commerce. 
Wiener, J., K. Liu, and G. Schieber. 1986. "Case-mix differences between hospital-based and freestanding skilled nursing facilities. A review of the evidence." Medical Care 24(12): 1173-82. 
Table 1: Characteristics of skilled nursing facilities (SNFs)

\begin{tabular}{|c|c|c|c|c|}
\hline & \multicolumn{2}{|c|}{$\begin{array}{c}\text { Freestanding } \\
\mathrm{N}=14,626\end{array}$} & \multicolumn{2}{|c|}{$\begin{array}{c}\text { Hospital-based } \\
\mathrm{N}=1,124\end{array}$} \\
\hline & Mean & SD & Mean & $\mathrm{SD}$ \\
\hline Total beds in SNF & 109.57 & 60.23 & 61.45 & 82.06 \\
\hline Facility is part of a chain & 0.56 & 0.50 & 0.32 & 0.47 \\
\hline Facility is run for-profit & 0.72 & 0.45 & 0.12 & 0.32 \\
\hline Located in urban county & 0.70 & 0.46 & 0.51 & 0.50 \\
\hline Percent occupancy & 83.45 & 15.08 & 77.96 & 21.18 \\
\hline Total registered nurse hours/day/resident & 0.38 & 0.69 & 1.68 & 2.22 \\
\hline Total licensed practical nurse hours/day/resident & 0.87 & 0.90 & 1.38 & 1.67 \\
\hline Total certified nurse aide hours/day/resident & 2.23 & 1.24 & 3.30 & 2.63 \\
\hline Admissions black (\%) & 10.36 & 17.38 & 7.56 & 14.04 \\
\hline Annual admissions/bed (\#) & 1.77 & 1.68 & 8.20 & 9.95 \\
\hline Proportion of SNF days per total nursing home days & 17.74 & 14.88 & 40.00 & 40.13 \\
\hline Average case mix index at admission to SNF & 1.05 & 0.11 & 1.07 & 0.16 \\
\hline Average ADL score on admission (0-28) & 16.18 & 3.00 & 15.31 & 3.59 \\
\hline Residents physically restrained (\%) & 3.77 & 6.19 & 2.56 & 7.17 \\
\hline Residents receiving antipsychotics $(\%)$ & 26.85 & 14.70 & 15.93 & 15.44 \\
\hline Non-psychotic residents receiving antipsychotics (\%) & 19.76 & 9.31 & 13.27 & 13.20 \\
\hline Weighted deficiency score, all deficiencies & 80.34 & 81.64 & 59.20 & 53.37 \\
\hline PPNH Hospitalizations per resident/year/SNF (\%) & 0.31 & 0.18 & 0.43 & 0.40 \\
\hline
\end{tabular}

Notes: $\mathrm{ADL}=$ activities of daily living; $\mathrm{PPNH}=$ potentially preventable nursing home 
Days in different setting in the 180 days following hospital discharge

Death (\# of days)

Hospital (\# of days)

Skilled nursing facility (\# of days)

Community with home health care (\# of days)

Community (\# of days)
25.19

8.29

51.01

28.44

67.06
52.79

18.02

52.00

38.47

63.85

\section{Accumulated outcomes in first $\mathbf{3 0}$ days following discharge}

Reimbursement for Inpatient hospital care (\$)

2,256

6,327

Reimbursement for SNF care (\$)

9,160

4,438

Reimbursement for Home health care (\$)

415

781

Total reimbursement (\$)

11,903

6,815

Death

0.071

0.257

Any hospital readmission

0.201

0.401

\section{Accumulated outcomes in first 180 days following discharge}

Reimbursement for Inpatient hospital care (\$)

8,214

14,413

Reimbursement for SNF care (\$)

2,545

25,790

Total reimbursement $(\$)$

0.220

0.446

16,978

10,673

3,299

22,151

0.414

Any hospital readmission

0.497 
Table 3: Person-level characteristics by differential distance (DD) between nearest hospital with $\mathrm{SNF}$ and nearest without $\mathrm{SNF}(\mathrm{N}=\mathbf{8 2 7 , 5 1 3})$

\begin{tabular}{|c|c|c|c|c|c|c|}
\hline \multirow[t]{2}{*}{$\mathrm{N}$} & \multicolumn{2}{|c|}{827,541} & \multicolumn{2}{|c|}{$\begin{array}{l}\text { IV below the } \\
\text { HRR level } \\
\text { Median } \\
392,400\end{array}$} & \multicolumn{2}{|c|}{$\begin{array}{c}\text { IV above the } \\
\text { HRR level } \\
\text { Median } \\
435,141\end{array}$} \\
\hline & Mean & SD & Mean & SD & Mean & SD \\
\hline \multicolumn{7}{|l|}{ Main explanatory variable } \\
\hline Hospital-based status & 0.12 & 0.33 & 0.17 & 0.38 & 0.07 & 0.26 \\
\hline \multicolumn{7}{|l|}{ Patient's demographic characteristics } \\
\hline Age & 81.34 & 7.86 & 81.18 & 7.87 & 81.49 & 7.85 \\
\hline Female & 0.66 & 0.48 & 0.65 & 0.48 & 0.66 & 0.47 \\
\hline Black & 0.07 & 0.26 & 0.08 & 0.26 & 0.07 & 0.25 \\
\hline Other race & 0.03 & 0.17 & 0.03 & 0.17 & 0.03 & 0.18 \\
\hline Dual eligible on the month of admission & 0.19 & 0.39 & 0.19 & 0.39 & 0.19 & 0.39 \\
\hline Married & 0.35 & 0.48 & 0.35 & 0.48 & 0.34 & 0.47 \\
\hline \multicolumn{7}{|l|}{ Patient's Clinical characteristics } \\
\hline Length of stay of index hospitalization & 7.78 & 5.92 & 7.82 & 5.93 & 7.74 & 5.91 \\
\hline $\begin{array}{l}\text { Number of days with home health use in } \\
30 \text { days before SNF admission }\end{array}$ & 2.58 & 6.69 & 2.53 & 6.64 & 2.62 & 6.74 \\
\hline Deyo index greater than 2 & 0.43 & 0.50 & 0.43 & 0.50 & 0.43 & 0.49 \\
\hline Elexhauser index greater than 2 & 0.51 & 0.50 & 0.51 & 0.50 & 0.51 & 0.50 \\
\hline ICU days in index hospitalization & 2.22 & 4.77 & 2.22 & 4.78 & 2.22 & 4.77 \\
\hline Diabetes & 0.30 & 0.46 & 0.30 & 0.46 & 0.30 & 0.46 \\
\hline Congestive heart failure & 0.21 & 0.41 & 0.21 & 0.41 & 0.21 & 0.41 \\
\hline Hip fracture & 0.09 & 0.28 & 0.09 & 0.28 & 0.09 & 0.28 \\
\hline Cerebrovascular Disease & 0.11 & 0.31 & 0.11 & 0.31 & 0.11 & 0.31 \\
\hline Bipolar disorder & 0.01 & 0.09 & 0.01 & 0.09 & 0.01 & 0.10 \\
\hline Schizophrenia & 0.01 & 0.07 & 0.01 & 0.07 & 0.01 & 0.07 \\
\hline Chronic Obstructive Pulmonary Disease & 0.20 & 0.40 & 0.20 & 0.40 & 0.20 & 0.40 \\
\hline $\begin{array}{l}\text { Number of medications taken in last seven } \\
\text { days }\end{array}$ & 12.17 & 4.83 & 12.25 & 4.87 & 12.10 & 4.78 \\
\hline $\begin{array}{l}\text { Morris additive Activity of Daily Living } \\
\text { (ADL) score }\end{array}$ & 16.54 & 5.31 & 16.49 & 5.35 & 16.58 & 5.28 \\
\hline $\begin{array}{l}\text { Fries/Morris cognitive performance scale } \\
\text { (CPS) }\end{array}$ & 1.29 & 1.53 & 1.28 & 1.54 & 1.30 & 1.53 \\
\hline CHESS & 1.55 & 1.03 & 1.54 & 1.02 & 1.56 & 1.03 \\
\hline Resource Utilization Group III & 6.06 & 1.83 & 6.02 & 1.85 & 6.10 & 1.81 \\
\hline $\begin{array}{l}\text { Patient's residential zip code } \\
\text { characteristics }\end{array}$ & & & & & & \\
\hline $\begin{array}{l}\% \text { of } 65+\text { age population under poverty } \\
\text { line }\end{array}$ & 9.14 & 6.15 & 9.36 & 6.41 & 8.94 & 5.93 \\
\hline
\end{tabular}


$\%$ of population with physical disability

\begin{tabular}{cc|cc|cc|}
26.74 & 6.87 & 27.01 & 7.19 & 26.51 & 6.59 \\
9.89 & 4.17 & 9.96 & 4.34 & 9.82 & 4.02 \\
& & 14.99 & 14.55 & 15.86 & 15.11 \\
15.45 & 14.84 & & & & \\
420.7 & 972.6 & 369.8 & 795.4 & 466.6 & 1132 \\
& & 7.35 & 15.86 & 6.67 & 13.89 \\
6.99 & 14.83 & & & & \\
& & & & & \\
200.3 & 145.7 & 199.7 & 139.0 & 200.8 & 152.2 \\
0.10 & 0.30 & 0.09 & 0.29 & 0.10 & 0.30 \\
0.11 & 0.31 & 0.08 & 0.27 & 0.14 & 0.35 \\
0.22 & 0.47 & 0.23 & 0.48 & 0.20 & 0.45 \\
3.14 & 1.80 & 3.20 & 2.03 & 3.08 & 1.52 \\
490.4 & 402.5 & 521.5 & 519.1 & 458.4 & 222.4 \\
96.65 & 49.36 & 97.56 & 57.44 & 95.72 & 39.35 \\
& & & & & \\
0.95 & 1.45 & 0.00 & 1.20 & 1.81 & 1.08 \\
& & & & & \\
\hline
\end{tabular}

Notes: CHESS = Changes in Health, End-stage disease, Signs and Symptoms scale 
Table 4: First-stage results, regression of a hospital with a skilled nursing facility (SNF) on differential distance

\begin{tabular}{|c|c|c|c|c|c|}
\hline & All & All & $\begin{array}{l}\text { Entered } \\
\text { hospital } \\
\text { 100km+ }\end{array}$ & $\begin{array}{l}\text { Entered } \\
\text { hospital } \\
200 k m+\end{array}$ & $\begin{array}{l}\text { Entered } \\
\text { hospital } \\
500 \mathrm{~km}+\end{array}$ \\
\hline $\begin{array}{l}\text { Differential Distance (natural log of } \\
\text { nearest hospital w/ SNF - natural log } \\
\text { of nearest w/out) }\end{array}$ & & $-0.0579 * * *$ & $-0.0135 * * *$ & $-0.0044 * * *$ & -0.00184 \\
\hline $\begin{array}{l}\text { Differential Distance (nearest hospital } \\
\text { w/ SNF - nearest w/out) }\end{array}$ & $-.0017 * * *$ & & & & \\
\hline$t$-statistics & 8.78 & 20.06 & 6.77 & 3.31 & 1.21 \\
\hline$F$-statistics & 77.01 & 402.40 & 45.87 & 10.98 & 1.47 \\
\hline Partial $R$-squared & 0.031 & 0.057 & & & \\
\hline Observations & 826,485 & 826,485 & 48,287 & 27,449 & 17,996 \\
\hline$R$-squared & 0.0927 & 0.104 & 0.041 & 0.037 & 0.035 \\
\hline
\end{tabular}


Table 5: Effects of being treated in a hospital-based skilled nursing facility (SNF) on the number of days in different settings in the 180 days following $\mathrm{SNF}$ admission $(\mathrm{N}=\mathbf{8 2 7 , 5 1 3})$

\begin{tabular}{|c|c|c|c|c|c|}
\hline & \multicolumn{5}{|c|}{ Number of days } \\
\hline & Death & Hospital & SNF & $\begin{array}{l}\text { Community } \\
\text { with home } \\
\text { health care }\end{array}$ & Community \\
\hline Unadjusted difference & $\begin{array}{c}-5.658 * * * \\
{[0.178]}\end{array}$ & $\begin{array}{l}-0.0896 \\
{[0.0608]}\end{array}$ & $\begin{array}{c}-21.93^{* * *} \\
{[0.174]}\end{array}$ & $\begin{array}{c}5.926 * * * \\
{[0.130]}\end{array}$ & $\begin{array}{c}21.75 * * * \\
{[0.214]}\end{array}$ \\
\hline Adjusted difference & $\begin{array}{c}0.951 * * * \\
{[0.169]}\end{array}$ & $\begin{array}{l}0.257 * * * \\
{[0.0614]}\end{array}$ & $\begin{array}{c}-14.12 * * * \\
{[0.167]}\end{array}$ & $\begin{array}{c}4.131 * * * \\
{[0.129]}\end{array}$ & $\begin{array}{c}8.781^{* * *} \\
{[0.184]}\end{array}$ \\
\hline $\begin{array}{l}\text { Adjusted difference with } \\
\text { HRR fixed effects }\end{array}$ & $\begin{array}{c}0.553 * * * \\
{[0.181]}\end{array}$ & $\begin{array}{l}0.469 * * * \\
{[0.0656]}\end{array}$ & $\begin{array}{c}-16.91 * * * \\
{[0.177]}\end{array}$ & $\begin{array}{c}5.038 * * * \\
{[0.136]}\end{array}$ & $\begin{array}{c}10.85 * * * \\
{[0.195]}\end{array}$ \\
\hline $\begin{array}{l}\text { IV with HRR fixed } \\
\text { effects }\end{array}$ & $\begin{array}{c}0.853 \\
{[0.760]}\end{array}$ & $\begin{array}{c}-0.607 * * \\
{[0.276]}\end{array}$ & $\begin{array}{c}-5.711 * * * \\
{[0.748]}\end{array}$ & $\begin{array}{c}0.704 \\
{[0.574]}\end{array}$ & $\begin{array}{c}4.761 * * * \\
{[0.819]}\end{array}$ \\
\hline
\end{tabular}

Note: Regressions reported in last three rows include patients and residential zip-code level explanatory variables listed in table 3. Standard errors are reported in square brackets and are based on robust standard error. 
Table 6: Estimated effect of being treated in a hospital-based skilled nursing facility (SNF) on Medicare spending, mortality, and hospital readmission in 30 days following hospital discharge $(\mathrm{N}=\mathbf{8 2 7}, \mathbf{5 1 3})$

\begin{tabular}{|c|c|c|c|c|c|c|}
\hline & \multicolumn{4}{|c|}{ Reimbursement (\$) } & \multirow[b]{2}{*}{ Any Death } & \multirow{2}{*}{$\begin{array}{l}\text { Any hospital } \\
\text { readmission }\end{array}$} \\
\hline & $\begin{array}{c}\text { Inpatient } \\
\text { hospital }\end{array}$ & SNF & $\begin{array}{l}\text { Home } \\
\text { health }\end{array}$ & total & & \\
\hline $\begin{array}{l}\text { Unadjusted } \\
\text { difference }\end{array}$ & $\begin{array}{c}-74.82 * * * \\
{[21.36]}\end{array}$ & $\begin{array}{c}-3,765 * * * \\
{[14.40]}\end{array}$ & $\begin{array}{c}421.1 * * * \\
{[2.596]}\end{array}$ & $\begin{array}{c}-3,432 * * * \\
{[22.70]}\end{array}$ & $\begin{array}{l}-0.0159 * * * \\
{[0.000867]}\end{array}$ & $\begin{array}{c}-0.0154 * * * \\
{[0.00135]}\end{array}$ \\
\hline $\begin{array}{l}\text { Adjusted } \\
\text { difference }\end{array}$ & $\begin{array}{c}-90.75 * * * \\
{[21.32]}\end{array}$ & $\begin{array}{c}-2,826 * * * \\
{[13.34]}\end{array}$ & $\begin{array}{c}345.0 * * * \\
{[2.555]}\end{array}$ & $\begin{array}{c}-2,566 * * * \\
{[22.03]}\end{array}$ & $\begin{array}{c}0.00609 * * * \\
{[0.000854]}\end{array}$ & $\begin{array}{c}-0.0179 * * * \\
{[0.00134]}\end{array}$ \\
\hline $\begin{array}{l}\text { Adjusted } \\
\text { difference with } \\
\text { HRR fixed effects }\end{array}$ & $\begin{array}{c}-56.50 * * \\
{[22.79]}\end{array}$ & $\begin{array}{c}-2,790 * * * \\
{[13.91]}\end{array}$ & $\begin{array}{c}373.5 * * * \\
{[2.703]}\end{array}$ & $\begin{array}{c}-2,456^{* * * *} \\
{[23.25]}\end{array}$ & $\begin{array}{l}0.00491 * * * \\
{[0.000913]}\end{array}$ & $\begin{array}{c}-0.0152 * * * \\
{[0.00144]}\end{array}$ \\
\hline $\begin{array}{l}\text { IV with HRR } \\
\text { fixed effects }\end{array}$ & $\begin{array}{c}-224.9 * * \\
{[95.89]}\end{array}$ & $\begin{array}{c}-2,871 * * * \\
{[58.55]}\end{array}$ & $\begin{array}{c}222.7 * * * \\
{[11.40]}\end{array}$ & $\begin{array}{c}-2,882 * * * \\
{[97.85]}\end{array}$ & $\begin{array}{l}0.00679 * \\
{[0.00384]}\end{array}$ & $\begin{array}{c}-0.0339 * * * \\
{[0.00597]}\end{array}$ \\
\hline
\end{tabular}

Note: Regressions reported in last three rows include patients and residential zip-code level explanatory variables listed in table 3. Standard errors are reported in square brackets and are based on robust standard error. 
Table 7: Estimated effect of being treated in a hospital-based skilled nursing facility (SNF) on Medicare spending, mortality, and hospital readmission in six months following hospital discharge $(\mathrm{N}=\mathbf{8 2 7 , 5 1 3})$

\begin{tabular}{|c|c|c|c|c|c|c|}
\hline & \multicolumn{4}{|c|}{ Medicare spending (\$) } & \multirow[b]{2}{*}{ Any Death } & \multirow[b]{2}{*}{$\begin{array}{l}\text { Any hospital } \\
\text { readmission }\end{array}$} \\
\hline & $\begin{array}{c}\text { Inpatient } \\
\text { hospital }\end{array}$ & SNF & $\begin{array}{l}\text { Home } \\
\text { health }\end{array}$ & total & & \\
\hline $\begin{array}{l}\text { Unadjusted } \\
\text { difference }\end{array}$ & $\begin{array}{c}-337.0 * * * \\
{[57.32]}\end{array}$ & $\begin{array}{c}-6,336 * * * \\
{[35.35]}\end{array}$ & $\begin{array}{c}332.4 * * * \\
{[11.13]}\end{array}$ & $\begin{array}{c}-6,520 * * * \\
{[74.44]}\end{array}$ & $\begin{array}{c}-0.0480 * * * \\
{[0.00140]}\end{array}$ & $\begin{array}{c}-0.0276^{* * * *} \\
{[0.00168]}\end{array}$ \\
\hline $\begin{array}{l}\text { Adjusted } \\
\text { difference }\end{array}$ & $\begin{array}{c}-331.3 * * * \\
{[56.90]}\end{array}$ & $\begin{array}{c}-4,440 * * * \\
{[33.98]}\end{array}$ & $\begin{array}{c}270.6 * * * \\
{[11.09]}\end{array}$ & $\begin{array}{c}-4,528 * * * \\
{[72.73]}\end{array}$ & $\begin{array}{c}0.0046 * * * \\
{[0.00133]}\end{array}$ & $\begin{array}{c}-0.0266^{* * * *} \\
{[0.00167]}\end{array}$ \\
\hline $\begin{array}{l}\text { Adjusted } \\
\text { difference with } \\
\text { HRR fixed } \\
\text { effects }\end{array}$ & $\begin{array}{c}-326.6 * * * \\
{[60.72]}\end{array}$ & $\begin{array}{c}-4,677 * * * \\
{[35.89]}\end{array}$ & $\begin{array}{c}413.8 * * * \\
{[11.70]}\end{array}$ & $\begin{array}{c}-4,550 * * * \\
{[77.23]}\end{array}$ & $\begin{array}{l}0.00127 \\
{[0.00142]}\end{array}$ & $\begin{array}{c}-0.0271 * * * \\
{[0.00178]}\end{array}$ \\
\hline $\begin{array}{l}\text { IV with HRR } \\
\text { fixed effects }\end{array}$ & $\begin{array}{l}-42.99 \\
{[255.4]} \\
\end{array}$ & $\begin{array}{c}-3,858 * * * \\
{[151.0]} \\
\end{array}$ & $\begin{array}{c}-56.57 \\
{[49.26]} \\
\end{array}$ & $\begin{array}{c}-4,196 * * * \\
{[324.9]} \\
\end{array}$ & $\begin{array}{c}0.00268 \\
{[0.00597]} \\
\end{array}$ & $\begin{array}{c}-0.0404 * * * \\
{[0.00751]}\end{array}$ \\
\hline
\end{tabular}


Table 8: Specification checks $(\mathrm{N}=827,513$ unless otherwise noted $)$

\begin{tabular}{|c|c|c|c|c|c|}
\hline & \multicolumn{5}{|c|}{ Number of days in a given setting } \\
\hline & Death & Hospital & SNF & HHA & Home \\
\hline \multirow{2}{*}{ Baseline model } & 0.853 & $-0.607 * *$ & $-5.711 * * *$ & 0.704 & $4.761 * * *$ \\
\hline & {$[0.760]$} & {$[0.276]$} & {$[0.748]$} & {$[0.574]$} & [0.819] \\
\hline \multirow{2}{*}{ Linear differential distance } & $-2.445 * *$ & $-1.371 * * *$ & $-6.207 * * *$ & $2.535 * * *$ & $7.488 * * *$ \\
\hline & {$[1.045]$} & [0.404] & {$[0.983]$} & {$[0.780]$} & {$[1.137]$} \\
\hline \multirow{2}{*}{$\begin{array}{l}\text { Binary DD measure } \\
\text { (above/below) median }\end{array}$} & -0.174 & $-0.708 *$ & $-7.111 * * *$ & 1.255 & $6.738 * * *$ \\
\hline & [1.080] & [0.387] & [1.068] & {$[0.810]$} & {$[1.165]$} \\
\hline \multirow{2}{*}{ Urban SNFs only $(\mathrm{N}=690,991)$} & $2.166^{*}$ & $-1.122 * *$ & $-2.900 * *$ & 0.231 & 1.625 \\
\hline & [1.221] & {$[0.454]$} & [1.195] & [0.927] & [1.328] \\
\hline \multirow{2}{*}{ Rural SNFs only $(\mathrm{N}=136,010)$} & -1.02 & 0.246 & $-10.15 * * *$ & $3.750 * * *$ & $7.170 * * *$ \\
\hline & [1.195] & {$[0.395]$} & {$[1.256]$} & {$[0.897]$} & {$[1.262]$} \\
\hline \multirow{2}{*}{$\begin{array}{l}\text { High competition markets }(\mathrm{N}= \\
768,508)\end{array}$} & 0.737 & $-0.570^{*}$ & $-5.134 * * *$ & 0.57 & $4.396 * * *$ \\
\hline & [0.882] & [0.318] & {$[0.874]$} & [0.667] & {$[0.957]$} \\
\hline \multirow{2}{*}{$\begin{array}{l}\text { Low competition markets }(\mathrm{N}= \\
58,493)\end{array}$} & 0.303 & -0.701 & $-5.731 * *$ & 2.906 & 3.223 \\
\hline & [2.354] & [0.845] & {$[2.483]$} & [1.792] & [2.441] \\
\hline \multirow{2}{*}{$\begin{array}{l}\text { Hip fracture patients } \\
(\mathrm{N}=69,352)\end{array}$} & -1.375 & $-2.523 * * *$ & $-7.158 * * *$ & $4.399 * *$ & $6.656 * *$ \\
\hline & [2.397] & {$[0.937]$} & {$[2.740]$} & {$[2.040]$} & {$[2.743]$} \\
\hline \multirow{2}{*}{$\begin{array}{l}\text { Acute myocardial infarction } \\
\text { patients }(\mathrm{N}=19,068)\end{array}$} & 3.346 & -1.755 & -2.803 & -2.966 & 4.178 \\
\hline & [6.892] & [2.196] & [5.944] & [4.549] & [6.562] \\
\hline \multirow{2}{*}{ Stroke patients $(\mathrm{N}=27,397)$} & 2.418 & 1.473 & $-10.49 * *$ & -0.286 & $6.881^{*}$ \\
\hline & [4.245] & [1.362] & [4.660] & {$[2.950]$} & [3.896] \\
\hline \multirow{2}{*}{$\begin{array}{l}\text { Model including hospital } \\
\text { characteristics }(\mathrm{N}=719,484)\end{array}$} & 0.985 & $-0.512 *$ & $-7.226 * * *$ & $1.410^{* *}$ & $5.342 * * *$ \\
\hline & {$[0.846]$} & [0.306] & [0.843] & {$[0.644]$} & {$[0.916]$} \\
\hline
\end{tabular}

Note: All the regressions excluding the last row include patients and residential zip-code level explanatory variables listed in table 3 and hospital referral region (HRR) fixed effects. Regressions reported in the last raw included hospital characteristics Standard errors are based on robust standard error. 
Figure 1: Fraction of skilled nursing facility (SNF) patients in state who were treated in a hospital that owned a SNF

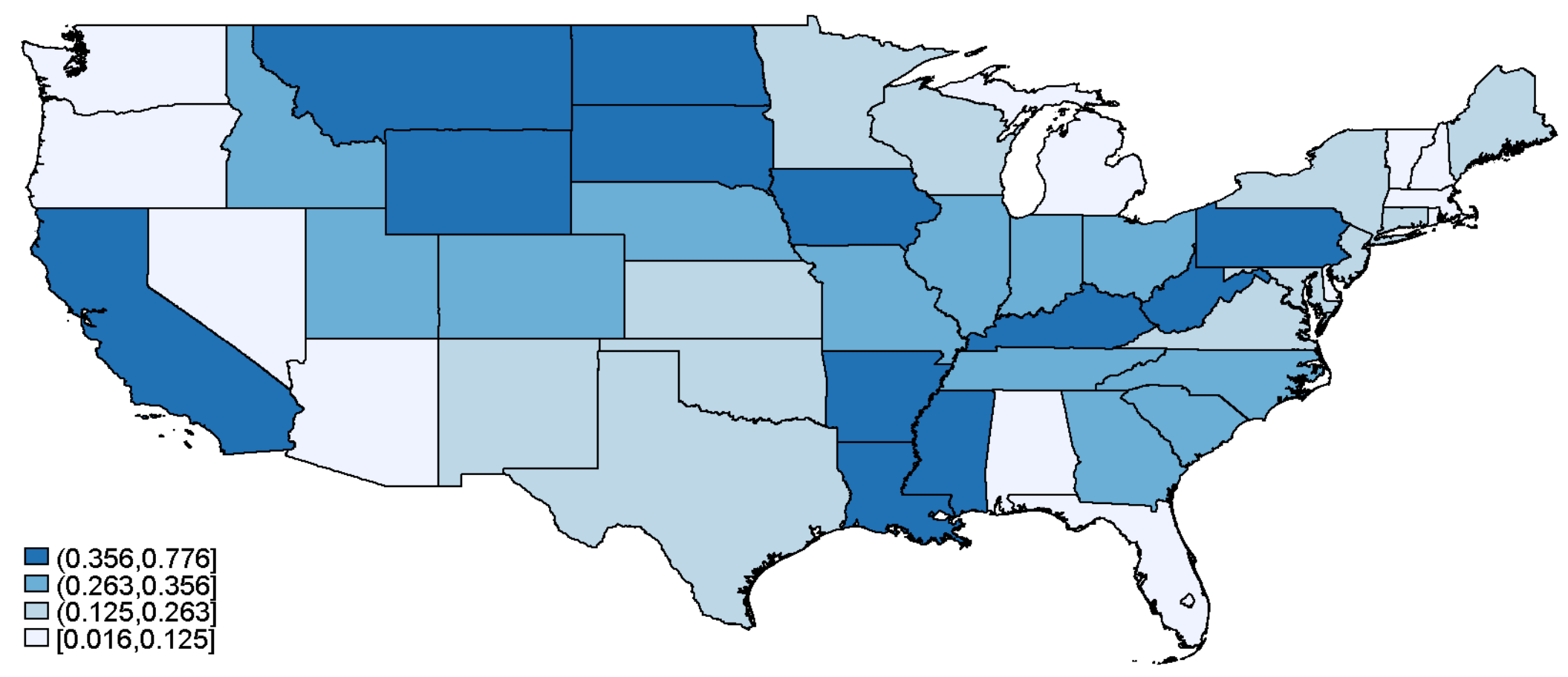


Figure 2: Fraction of patients in a given setting in days following hospital discharge

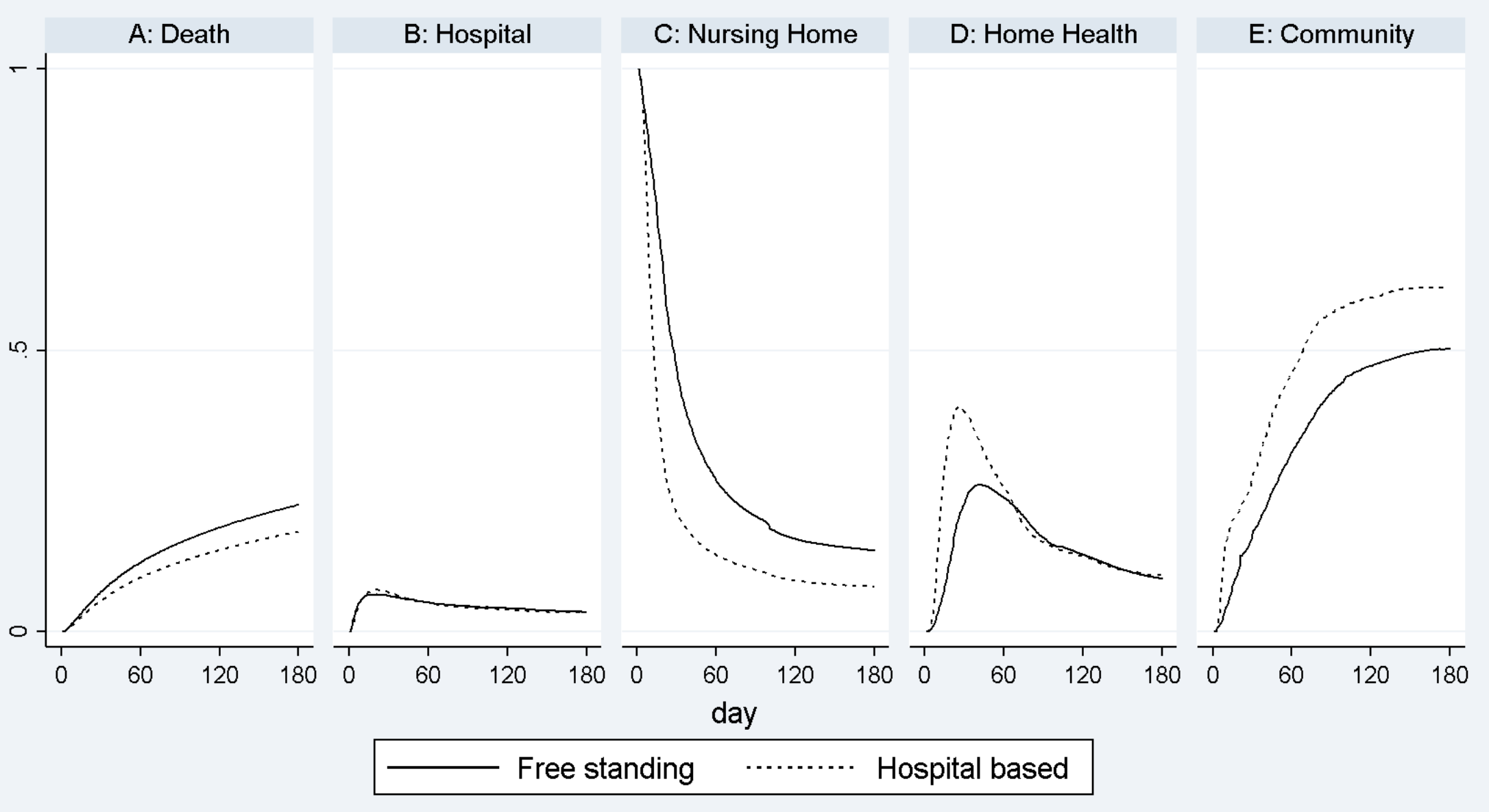


Figure 3: Instrumented impact of being discharged to hospital-based skilled nursing facility

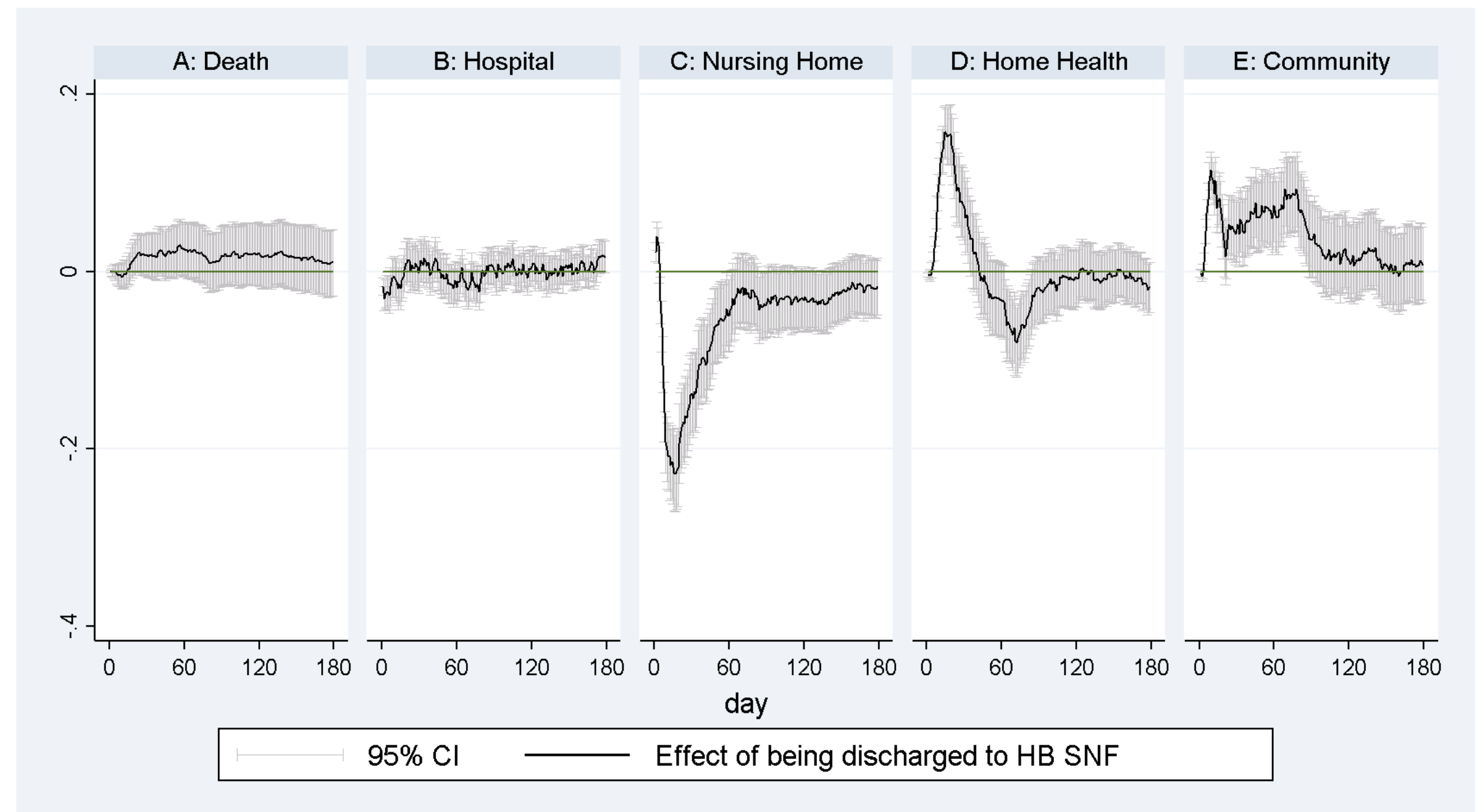

